http://jmscr.igmpublication.org/home/

ISSN (e)-2347-176x ISSN (p) 2455-0450

crossref DOI: https://dx.doi.org/10.18535/jmscr/v7i7.155

Journal Of Medical Science And Clinical Research

\title{
Review Pharmacology practical curriculum
}

\author{
Authors \\ Dr Anupam Nath Gupta ${ }^{1 *}$, Dr Paras Nath ${ }^{2}$ \\ ${ }^{1}$ Associate Professor, Department of Pharmacology, North Bengal Medical College, Datjeeling, \\ West Bengal \\ ${ }^{2}$ Medical Officer, Department of Obstetrics and Gynecology, Siliguri District Hospital, Siliguri, \\ West Bengal \\ *Corresponding Author \\ Dr Anupam Nath Gupta
}

Associate Professor, Department of Pharmacology, North Bengal Medical College, Datjeeling, West Bengal

\begin{abstract}
The Indian medical graduate as the name itself speaks a lot, for making this successful the teaching in $M B B S$ is power key. Pharmacology is the mother subject in MBBS. For the betterment of future changes are always required according to the changes in requirements and utility of current scenario. This study was done with the aim of assessment of efficiency of teaching of Pharmacology in MBBS and its betterment. Keywords: Pharmacology curriculum MBBS.
\end{abstract}

\section{Introduction}

Pharmacology is not just restricted to the study of drugs as the name may suggest. It has evolved over the years and now pharmacology is a vast discipline, which not only teaches the undergraduate students

about the drugs and their mechanisms, but also rational and safe prescribing and related skills. ${ }^{1}$ The challenges involved in teaching pharmacology in an integrated curriculum include the need to ensure that a core disciplinary curriculum can be identified and mapped to the new structure, and that students are introduced to key scientific concepts and information in an order that builds from a sound scientific base to the more clinically applied knowledge. ${ }^{2}$

Pharmacology teaching during undergraduate course is thus aimed at making better clinical practitioners in future. ${ }^{3}$ The task of embedding pharmacology in an integrated medical curriculum is not a simple one. As we have demonstrated, it involves the close cooperation of pharmacologists with their fellow scientists from other disciplines as well as with educational designers and clinicians. It is possible, however, to gain the benefits of integration without sacrificing student learning of fundamental concepts of the discipline as well as their application in the clinical setting (Garg et al., 2004). ${ }^{(1)}$

\section{Materials and Methods}

A questionnaire-based study was carried out in North Bengal Medical College for 4 months duration. The purpose of the study was briefed to concern authority. A pre tested semi-structured questionnaire was given to the faculties of 
different departments, medical officers and interns after taking written consent. The questionnaire contained questions pertaining to perception about relevance of pharmacology learning experiences and their confidence in prescribing and related skills to the prescription parts, label marking and names of ten pharmacology practical instruments ,Preparation of carminative mixture, ORS, potassium permanganate, atropine ointment were also included in the questionnaire (Annexure-I). The participants also gave their opinion about the utility of the existing pharmacology practical class in undergraduate curriculum. Data were computercoded and analysed using statistical package SPSS 12.0

\section{Results}

Out of 114 medical students and teachers, 94 participated in the study. Among them, 43.6\%, $29.8 \%$ and $26.6 \%$ were medical teachers and officers and interns and postgraduate students. They were interrogated about different aspects of practical classes of pharmacology held during their MBBS course. The duration after passing the MBBS course were also noted. This study could obtain data from $41.5 \%$ within ten years of passing who were mainly interns, postgraduate students and some young teachers. About 33\% and $25.5 \%$ have passed their MBBS course within 10-20 years and more than 20 years respectively. The parts of prescription are recalled correctly in $22.3-11 \%$ cases in various groups (Table 1 ). The procedure of different pharmacological preparations is remembered in only in $5-13 \%$ cases out of which, highest recall level was in medical teachers. The difference is statistically significant. The important statistical significance is seen in label making varies from $6-21 \%$ (the maximum positive results from medical teachers especially of pharmacology). Table 2 depicts the utility of the practical classes held in pharmacology course curriculum among the different tiers of health personnel. Less than $20 \%$ of interns, PGTs commented that it is helpful in their day to day life. $23.4 \%, 18.1 \%$ and $14.9 \%$ enjoyed the experimental laboratory classes in their learning period of MBBS course and the difference is found to be statistically significant. It was also revealed from the study that $83 \%$ of the study population opted for a change in curriculum of the pharmacology practical course whereas $17 \%$ did not want any change.

Table 1 Recall of different parts of pharmacology practical classes among health care personnel.

\begin{tabular}{|c|c|c|c|c|}
\hline \multirow[t]{2}{*}{ Variables of pharmacology practical } & \multirow{2}{*}{$\begin{array}{l}\text { Interns and } \\
\text { PGTs }(n=25)\end{array}$} & \multirow[b]{2}{*}{$\begin{array}{l}\text { Medical officers } \\
\qquad \mathrm{N}=28\end{array}$} & \multicolumn{2}{|c|}{ Medical teachears } \\
\hline & & & $\mathrm{n}=41$ & Significant test \\
\hline Prescription part & $21(22.3 \%)$ & $11(11.7 \%)$ & $21(22.3 \%)$ & $\kappa^{2}=11.526, p=0.003$ \\
\hline ORS preparation & $17(18.1 \%)$ & $7(7.4 \%)$ & $21(22.3 \%)$ & $\kappa^{2}=10.112, p=0.006$ \\
\hline Carminative mixture & $5(5.8 \%)$ & $5(5.8 \%)$ & $7(8.1 \%)$ & $\kappa^{2}=1.249, p=0.536$ \\
\hline Preparation of potassium permanganate & $5(5.8 \%)$ & $7(8.1 \%)$ & $13(15.1 \%)$ & $\kappa^{2}=0.364, p=0.834$ \\
\hline Preparation of atropine ointment & $8(8.5 \%)$ & $3(3.2 \%)$ & $4(4.3 \%)$ & $\kappa^{2}=6.547, p=0.038$ \\
\hline Label marking & $6(6.4 \%)$ & $\mathrm{c} 6(6.4 \%)$ & $21(22.3 \%)$ & $\kappa^{2}=8.326, p=0.016$ \\
\hline Name 10 instruments & $15(16.0 \%)$ & $10(10.6 \%)$ & $7(7.4 \%)$ & $\kappa^{2}=12.795, p=0.002$ \\
\hline
\end{tabular}

Table 2 Opinion of practical classes held in pharmacology during their undergraduate course among the medical personnel.

\begin{tabular}{lcccc}
\hline $\begin{array}{l}\text { Variables of pharmacology } \\
\text { practical }\end{array}$ & $\begin{array}{c}\text { Interns and } \\
(n=25)\end{array}$ & $\begin{array}{c}\text { Medical officers } \\
(n=28)\end{array}$ & $\begin{array}{c}\text { Medical teachers } \\
(n=41)\end{array}$ & Significant test \\
\hline Help in day-to-day life & $16(17.0 \%)$ & $10(10.6 \%)$ & $6(6.4 \%)$ & $\kappa^{2}=16.905, \mathrm{p}=0.000$ \\
Enjoy experimental lab & $22(23.4 \%)$ & $17(18.1 \%)$ & $14(14.9 \%)$ & $\kappa^{2}=18.651, \mathrm{p}=0.000$ \\
\hline
\end{tabular}




\section{Discussion}

Pharmacology being both a basic and applied science forms the back bone of rational therapeutics. The primary objective of teaching pharmacology is to enable undergraduate medical students to take rational therapeutic decisions in clinical practice. However, this objective is not adequately met by the prevailing curriculum. The subject is taught with high factual information rather than therapeutic skills (Vasundhara et al., 2011). This study has substantiated the view that the existing practical curriculum which have become now inadequate for preparing the medical students for clinical practice

The data were compiled and analysed. The study indicated that relevance of pharmacy practical knowledge in patient care is poor (Vasundhara et al., 2010). About $93 \%$ participants were unable to answer the very basics of pharmacy practical; the most probable reason behind is no use of the basics in day-to-day practice in doctors life. In this study, only $17 \%$ agreed for continuation of the same curricula of pharmacy practical in second year MBBS. According to this study findings, current practical curricula of pharmacology is obsolete and out dated and has failed to achieve the objective for which they were instituted (Heaton et al., 2008). This study upholds the view that there is an imperative need to implement radical changes in the teaching curricula of practical pharmacology which should be in commence with patient care for the doctors of tomorrow to render better health service. One very important point in our study has been noted that the recall memory for different pharmacy preparations from medical officers was only 3$7 \%$. These results reveal that there is no practical implication of present practical curricula.

The revised curriculum that was implemented from the year 2007 has three divisions, namely, clinical pharmacy, clinical pharmacology and experimental pharmacology. Clinical pharmacy includes drug formulations and relevant instructions, calculating the rate of infusion and setting IV infusion at that rate, calculating dose according to body weight and body surface area (BSA), sources of drug information. Clinical pharmacology includes prescription writing

for common conditions, P-drug selection (Personal drug), ${ }^{10}$ ADR reporting and critical evaluation of promotional drug literature and rationality of fixed dose combinations. Experimental pharmacology that includes the interpretation of the results from records, occupies less than $15 \%$ of the total curriculum and less than $10 \%$ in assessment. ${ }^{(3)}$

\section{Conclusion}

This study reveals that overall the undergraduate pharmacology curriculum has been relevant for rational prescribing. However, there are several areas that need more emphasis for future training in making the doctors more proficient in prescribing and related skills. ${ }^{(3)}$

The different suggestions for the betterment of present curricula from participants were: The skills required for the therapeutic reasoning and prescribing should be addressed and taught in a structured way. Exposure of medical students is needed in different pharmaceutical companies to teach how drugs are prepared. There is also need to include teaching of clinical pharmacology. There is need to train students about the critical evaluation of drug promotion. Teaching about pharmacoeconomics, pharmacogenomics and pharmacovigilance are useful (Jacson et al., 2004).

\section{References}

1. Aronson JK, Henderson G, Webb DJ, Rowlins MD. A prescription for better prescribing. BMJ 2006; 333(7566):459-60.

2. Garg, A., Rataboli, P.V. and Muchandani, K. 2004. Students' opinion on the prevailing teaching methods in pharmacology and changes recommended. Ind. J. Pharmacol. 36(3): 155-158.

3. Badyal DK, Bala S, Kathuria P. Student evaluation of teaching and assessment methods in pharmacology. Indian $\mathbf{J}$ Pharmacol 2010; 42(2): 87-9. 


\section{JMSCR VoI||07||Issue ||07||Page 878-881||July}

4. Hariharan, T.S. 2004. Need for changes in the practical pharmacology curriculum of medical undergraduates. Ind. J. Pharmacol.pp.36-181.

5. Heaton, A., Vvebb, D. and Maxwell, S. 2008. Undergraduate preparation for prescribing: The views of 2413 UK medical students and recent graduates. $\mathrm{Br}$. J. Clin. Pharmacol. 66: 128-134.

6. Jacson, S.H., Mangoni, A.A. and Batty, G.M. 2004. Ootamization of drug prescribing. Br. J. Pharmacol. 57: 231-236.

7. Vasundhara, K., Kanchan, P., Pundarikaksha, H.P., Girish, K., Prassana, S. and Jyothi, R. 2010. An imperative need to change pharmacology curriculum: A pilot survey. Ind. J. Pharmacol. 42(6): 120.

8. Vasundhara, K., Pundarikaksha, H., Vijendra, R., Girish, K., Jyothi, R. and Srinivasa, P. 2011.Existing and expected practical medical pharmacology curriculum-A survey. J. Clin. Diagnostic Res. 5(2): 340-343. 